\title{
ADDRESS IN MEDICINE,
}

BY

\author{
ALFRED HUDSON, M.D., F.K.Q.C.P., M.R.I.A., \\ Regius Professor of Physic in the University of Dublin.
}

\section{LAENNEC: HIS LABOURS, AND THEIR INFLUENCE} IN MEDICINE.

When the Council of the British Medical Association did me the honour to nominate me to deliver the Address in Medicine on the present occasion, my great difficulty was the choice of a suitable subject : what to select from the wide field of the past, present, and future of medicine. For not only do subjects of especial interest seldom present themselves, but, moreover, while on these occasions there is, among men engaged in so serious and engrossing a pursuit as ours, much interchange of serious thought and of practical suggestion, it may be questioned if the motive of our coming together is so much a desire to learn, as a feeling that (to borrow the language of an eloquent prelate) "whatever takes us out of ourselves and throws us back into the past or forwards into the future, does us good if it makes us spend a few happier hours and relieves us from the weary monotony and the heavy drudgery of life".

To attempt a review of the triumphs of the present and recent past would be to follow, by unequal steps, in the path of those who have so ably and exhaustively treated the subject on many previous occasions, and to repeat to-day what you have read in the retrospects, records, and journals of yesterday; while to pourtray the glories of the future of medicine would require a prescience which I do not possess; besides, having arrived at an age when a man naturally becomes a laudator temporis acti, I felt attracted to the consideration of the more remote past, and I resolved to offer a few observations on the history of its several epochs and of their representative men, and more especially of the great revolution which was in progress in my student days, when the era of nosology was superseded by that of pathology; when the theoretical deductions of Cullen and his predecessors were replaced by the inductive method of the present day, as inaugurated by Laennec.

In a comprehensive review of the past, three things attract our attention: its history, its progress, and the lives of the men who have marked its successive epochs.

Such a task differs from that of the student, or of the worker of the present day, in that, while the one necessarily seeks for advanced knowledge in the most recent sources, and the other founds his conceptions on those of his more immediate predecessors, a retrospect of the kind involves some notice of men whose works are now obsolete, and whose names have become mere traditions in the history of the science.

Its history has not always been one of progress, but rather a record of barren hypotheses and fanciful systems; of the lives and labours of men, often of marvellous ability and industry, whose aim was to attain that which was unattainable:

\section{"Crying for the light,
And with no language but a cry".}

These men have been sometimes compared to giants, who, taking us in their arms and lifting us above their heads, have disclosed to us countries and prospects which they themselves could never discover. Living before their age, and being unable to explain observed phenomena by the aid of the imperfect science of the time, they resorted to hypotheses evolved out of their own consciousness, which were really not explanatory of diseased processes, while their ideas of therapeutics were made to correspond with these imaginary conditions. Not that their labours were altogether useless ; for, as has been well said : "As in the growth and development of the body the daily death of the tissues is in strict relation with the activity of life, so in the organic growth of thought through the ages there is a corresponding decay or consumption of erroneous doctrines-a death of the false in strict relation with the growth of the true."

The comparison of the growth and development of science to that of the human body is by no means a novel one, and it is employed by Lord Bacon in terms peculiarly applicable to clinical medicine : "As young men", says Bacon, "when they knit in shape and perfectly, do seldom grow to a further stature, so knowledge, while it is in aphorisms and observations, is in growth ; but when once it is comprehended in exact methods, it may, perchance, be farther polished and illustrated, and accommodated for use and practice, but it increaseth no more in bulk and substance." The different stages of this comparison of progress correspond with the lives and labours of the great men who have marked the successive epochs of the science. While those of Harvey and of Haller are associated with the birth and progress of physiology, and Hunter is commemorated periodically as the founder of scientific surgery, the great names of Hippocrates, Morgagni, and Laennec correspond to the eras of aphorism, observation, and method, which each of them in turn illustrated by his life and works-each life, moreover, affording practical lessons of value. Thus the life of Hippocrates teaches the value of that early acquaintance with the objects of his future study, now too much overlooked. We are told that "amid the sports of childhood he received from the mouths of his parents the elementary notions of medical science. By viewing diseases, he learnt to distinguish them". Himself convinced of the superiority of this method of practical instruction, Hippocrates wrote: "In order to improve to a certain degree the knowledge and practical skill of the physician, it is necessary (independent of natural genius, the place of which nothing indeed can supply) that he be placed from early infancy amid all the objects of his researches, and that every means of instruction be employed with unremitting assiduity."

Of the character of his writings, Cabanis remarks : "He brought the science back again to its natural channel, that of rational experience. He freed medicine from false theories, and formed for it sure and solid systems. His books of aphorisms have in all ages been regarded as models of grandeur of conception and precision of style. Through the whole of them we may remark that truly universal method, the only one which is adapted to the mode in which our intellectual faculties are exercised, and which in every art and in every science, by making the principles flow naturally from the observations that have been collected, transforms the deductions from facts into general rules." This writer adds; "If the disciples of Hippocrates had understood his lessons well, they might have laid the foundation of that analytical philosophy by the aid of which the human mind will be henceforth enabled to create to itself, as it were daily, some new and improved instruments of advancement." It is scarcely necessary to remark how exactly this prediction has been realised in the history of physical diagnosis and in the life of Laennec.

The traditions of Hippocrates and his natural method, having outlived the centuries of dogmatism and of successive systems, have survived to the present day, transmitted through the dark ages of medicine in the aphorisms of Lommius, Baglivi, Boerhaave, Stoll, and othersaphorisms which, while comparatively free from the dogmatism of the age, contain matter of the highest practical value. One of the most illustrious of these writers (Baglivi) devotes two chapters to treating of the hindrances (impedimenta) of progress arising from neglect of ancient aphorisms and observations, and love of new systems, maintaining that "the entire value of the history of diseases depends on the careful and patient description of that which the observer, skilled in the mode of invasion, the progress, and issue of diseases, has perceived".. The writings of these men, like those of their great master, are especially distinguished by the fidelity of their descriptions of symptoms and the sagacity with which they anticipated sequences. They read the prognostic signs of disease with an accuracy and an insight whose

$$
\text { "To something like prophetic strain", }
$$

and are for these reasons, if for no other, worthy of the careful study of the practitioner. By the side of these names we place that of the English Hippocrates, Sydenham, the great observer, who, says the editor of his works, now stands out, at nearly the end of a second century, as the great representative of the practical medicine of practical England.

The influence of Sydenham is especially seen in the writings of the succeeding century, of Grant and Huxham, of Pringle, and others whom a distinguished American writer on fever terms "those glorious old British observers - the types and ornaments of a school never since surpassed by their countrymen". And I may here remark that the study of these and the abovementioned older writers would greatly tend to moderate extravagance of doctrine and exclusive devotion to special methods of treatment in our own day. These British writers, as Dr. Bartlett observes, clearly recognised the distinction between the two great forms of continued fever, which the great majority of the British physicians in his day "refused to admit, or to endeavour to ascertain"; while, of the wisdom and breadth of their views of treatment, no higher

* It is worthy of remark that in the course of a discussion on the subject of education in the General Medical Council in 1877 . Sir James Paget stated, as the result of tion in the General Medical Council in 1877 . Sir James Paget stated, as the result of
his own experience, that everything is in favour of putting a student at once to the daily honest practice of his profession by apprenticeship in the country for the first year. (Reported in the Medical Times and Gazette of June 2nd, 1877.) 
testimony need be adduced than the candid acknowledgment of Dr. Stokes, who says in his memoir on the state of the heart and use of wine in typhus fever: "I confess that it was not until several years after I commenced practice that I became fully aware of the erroneousness of what is termed the anatomical theory of disease; and I feel certain, humiliating though the confession may be, that the fear of stimulants, with which I was imbued, was the means of my losing many patients, whose lives would have been saved had I trusted less to the doctrine of inflammation and more to the lessons of experience given to us by men who observed and wrote before the times of Bichat or of Hunter."

I would add one remark to the above. It is, that a careful perusal of the excellent, albeit somewhat antiquated, chapter of Lommius on the diet of a fever patient, might help to guard the young practitioner from the too prevalent perversion and abuse of Graves's famous saying, ¿He fed fevers".

In England, these great observers were succeeded by others scarcely less noteworthy; by Fothergill and Fordyce, Heberden and Currie, whose writings will live as long as the art is cultivated.

Contemporary with these men were others: men of great ability, but who aimed at generalisations rather than observation, and strove to construct systems to which the medicine of the future should conform. I need not tell you that the systems of Cullen, of Brown, and of Darwin, have long become things of the past and forgotten.

But we pass on to the epoch of Pathology and Clinical Medicine inaugurated by Morgagni and his contemporaries and successors. In an admirable address, delivered before the Glasgow Pathological and Clinical Society in 1864, Professor Gairdner thus tersely describes the character of Morgagni's work.

"In investigating the seats of diseases, Morgagni is not content to record the coincidence of a lesion in an organ with the symptoms appa. rently due to disordered function in that organ.

"For the first time almost in the history of medical inquiry, he insists on examining every organ, as well as the one suspected to be chiefly implicated; not only so, he marshals with the utmost care from his own experience and that of his predecessors, all the instances in which the symptoms have existed apart from the lesion, or the lesion apart from the symptoms. He discusses each of these instances with severe exactness in the interest of truth, and only after an exhaustive investigation will he allow the inference either that the organ referred to is, or is not, the seat of the disease.

"And in like manner in dealing with causes: a group of symptoms may be caused by certain organic changes-it may be even probable that it is so-but, according to Morgagni's method, we must first inquire into all the lesions of organs which occur in connection with such symptoms; in the second place, we must know if such lesions ever occur, or occur without the symptoms; and, again, if such symptoms can be attributed in any cases to other causes in the absence of such lesion."

Did time permit, I would fain add to Dr. Gairdner's illustrations some examples of the glimpses of facts pointing to future observations and discoveries which are scattered through the portion of Morgagni's work relating to thoracic diseases. Such are his remarks on the con. nection between disordered states of the nervous system and deranged respiration (Letter 15); his notice of the sound heard on applying the ear to the pracordial region in a case of pericardial effusion (Letter 16); of the decubitus in empyema and the displacement of the liver in that;is. ease; of the signs of dilatation of the right ventricle, and the clear explanation of the phenomenon of jugular pulsation, and the wonder he expresses that the increased bulk of the heart is not attended to in the histories of asthma ; and of the curious case (quoted by Wardrop in his work on the heart) of alteration in the radial pulse, caused by a fall on the spine, and inexplicable until the discovery of the vaso-motor system of nerves; to lesions of which similar cases have been referred by Dr. Russell Reynolds and Dr. J. W. Ogle.

To those who, like Dr. Gairdner, look to what Morgagni has done for patholngy and clinical medicine "in the light not only of his own researches, but of those of his successors", it would seem difficult to over-estimate the value of his work and influence. But that the work itself was regarded by his more immediate successors rather as a record of symptoms and morbid appearances than an exposition of morbid processes in the living body, as wanting the explanatory why, and consequently of little assistance to the practitioner at the bedside, appears from the language of Corvisart, who, after stating that it will immortalise its author, adds the remark that this great work " neither helped nor hastened the art of cliagnosis"; adding, in a foot-note, that "he himself had formerly read a memoir to the Institute, expressing the idea of a work analogous, but in an inverse sense from that of Morgagni, with the titlc 'De sedibus et causis morborum per signa dingnostica investigatis, et per anatomen confirmatis'; but that, for such a work, at least another Morgagni would be required"."

The hour and the man were both at hand; and, as it has been said of Harvey, "that on the doctrine of the circulation the dawn had long been visible", and when Harvey came the sun arose; "so Laennec appeared, and realised the prevision of Corvisart by substituting a living for a dead pathology, and revolutionising clinical medicine by a method of diagnosis which, by revealing the seat, nature, and progress of disease at the bedside, anticipated the disclosures of the post mortem theatre, and endued the dry and unexplained facts of both symptoms and morbid appearances with meaning and with power".

"Time", says Dr. Stokes, " has shown that the introduction of auscultation and its subsidiary physical signs has been one of the greatest boons ever conferred by the genius of man on the world.

"A new era in medicine has been marked by a new science, depending on the immutable laws of physical phenomena, and, like the discoveries founded on such a basis, simple in its application and easily understood-a gift of science to a favoured son; one by which the ear is converted into the eye, the hidden recesses of visceral disease opened to view; a new guide to the treatment, and a new help to the early detection, prevention, and cure, of the most widely spread diseases which affect mankind."

I have alluded to men who lived before their time, who were in ad. vance of their age; Laennec was fortunate in living at the exact period at which he did, when Bichat had just created the science of general anatomy, and Haller and Hunter that of physiology; when Morgagni had grouped such a mass of his own observations and those of others on the results of disease as to entitle him to be called the founder of morbid anatomy; and when the first essay in physical diagnosis by Auenbrugger, long neglected, had been taken up and translated by Corvisart, who employed percussion as an aid to the diagnosis of cardiac diseases with much success. Laennec had thus, in the works of his immediate predecessors, the materials necessary for his system, which needed only the spark of his genius to burst into life and beauty.

I cannot but think it also fortunate that he did not live at a later period. He might perhaps have then anticipated some of the improvements which have followed from the modern advances in the correlated sciences; but I can imagine that, had the pathological anatomy of the period ripened into the histology of the present day-a science which, says Dr. Gairdner, "can only be sounded through the absolute devotion of a lifetime to its new methods of research"- his active and inquiring mind might have been altogether diverted from the study of the diagnosis of disease at the bedside to the researches of the dead-ronm and the laboratory, which, however important, must be held to be subordinate and secondary to the other. Laennec would seem to have so regarded it, when he wrote that "if the causes of severe diseases are sought for in mere microscopical alterations of structure, it is impossible to avoid running into consequences the most absurd; and, if once cultivated in this spirit, pathological anatomy, as well as that of the body in a sound state, will soon fall from the rank which it holds among the physical sciences, and become a mere tissue of hypotheses, founded in optical illusions and fanciful speculations, without any real benefit to medicine."

The life of Laennec, like the lives of other illustrious men, is not without its lessons. Although of feeble constitution and delicate health, it was marked by mental activity and incessant work. Like his great prototype Hippocrates, be became early familiar with disease, and, while a youth, showed a decided predilection for morbid anatomy and clinical observation, the future studies of his life. At the early age of eighteen, he served as assistant-surgeon in the military hospitals, and in the following year he became a pupil of Corvisart at La Charitć. Here he proved his diligence in the study of clinical medicine by drawing up a minute history of nearly four hundred cases of disease, which, it is known, furnished the groundwork of all his future researches and discoveries.

On taking his degree, he wrote a thesis on the cloctrine of Hippocrates, as applied to practical medicine, which, says M. Bayle, proved him to be no less skilled in the knowledge of the Greek language than deeply read in the writings of the father of physic. 'In the previous year, he had commenced a course of lectures on pathological anatomy, which he continued for three years, when ill-health obliged him to discontinue them. From this time until $1 S_{16} 6$, he continued to contribute articles on general and morbid anatomy to the Dictionary of Medical Sciences, and other publicntions; but on his appointment as

Dans un des memoires yue j'ai lus anciennement A l'Institut j'avais émis l'idé d'un ouvrage analogue mais en sens incerse pourtant it celui de Morgagni; il anrait

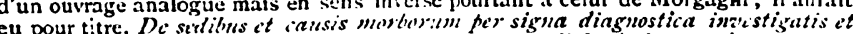
fer auten un tel ouvrage il foudrait au moins un : utre

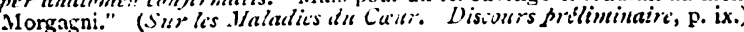


physician to the Necker Hospital-they ceased, and having made the discovery of mediate auscultation, he devoted himself solely to the perfecting of the new system of diagnosis which he founded on it, and to the clinical teaching of his method to the numerous students who resorted to him.

The history of this discovery is well known, but Laennec's observations on it are too important to be passed over without notice. "From this moment," says he, "I imagined that the circumstance might furnish means for enabling us to ascertain the character, not only of the action of the heart, but of every species of sound produced by the motion of the thoracic viscera, and, consequently, for the exploration of the respiration, the voice, the rattle or rhonchus, and perhaps even the fluctuation of fluid extravasated in the pleura or pericardium. With this conviction, I forthwith commenced at the Hospital Necker a series of observations, which have been continued to the present time. The consequence is, that $I$ have been enabled to discover a set of new signs of diseases of the chest, for the most part certain, simple, and prominent, and calculated, perhaps, to render the diagnosis of the diseases of the lungs, heart, and pleura as decided and circumstantial as the indications furnished to the surgeon by the introduction of the finger, or sound, in the complaints where these are used."

I have quoted this passage at length, as showing the strictly inductive character of the process of this discovery : first the observed fact, followed immediately by the anticipation based on previous knowledge of the pathological conditions of other diseases; then the repeated experimental trials, and the confirmation of the anticipation by repeated post mortem examinations.

The narrative illustrates several important principles common to the histories of scientific discovery.

First, it was apparently, but only apparently, accidental. "Men", says Whewell, "are fond of repeating that such discoveries are most commonly the result of accident; and we have seen reason to regret this opinion, since that preparation of thought by which the accident produces the discovery is the most important of the conditions on which the successful result depends." Then, it conformed to the usual conditions, viz., distinct general notions, careful observation of many facts, and the mental act of bringing together these elements of truth.

Regarded as an epoch in scientific discovery, this, like other inductive epochs, had a prelude in the preceding period, which led immediately up to it, and to which I have already referred. It has also had a sequel of verification and connection during which the discovery has acquired a more perfect certainty and a more complete development among the more advanced thinkers and improvers, has been diffused to the wider throng of the secondary cultivators, and traced into its distant consequences in its influence on the practice and teaching of medicine and on the status of the profession.

This discovery, nevertheless, did not at first excite much interest in the profession generally. It was announced in the Edinburgh Medical Fournal of the day in these terms: "M. Laennec has discovered that, by interposing a tube of paper or wood between the ear of the observer and the chest of the patient, much information may be acquired concerning the diseases of the chest. The pulsations of the heart are thus rendered more audible, and in phthisical patients the voice seems to proceed from the chest when one end of the tube is placed over those places where there are tubercles, and, according as the sound is clear or rattling, we may judge whether the cavity is clear or contains pus."

After such a notice, it is not surprising that the practitioners of the day did not much concern themselves about the new method of diagnosis, or that Sir John Forbes should write, three years after the appearance of his translation, that up to that time not even a single case of the use of auscultation had appeared in any British medical journal. Some of us can remember how the stethoscope and its inventor were sneered at and ridiculed by a few of the teachers of our own day. The new light was too strong for older eyes; and it is possible that, had not Laennec survived his discovery for.some years and continued to demonstrate its employment and results to the younger generation, it might have left as slight an impression on the minds of the profession as had the treatise on percussion by Auenbrugger, which preceded it.

Sir James Paget tells us that, "although Hunter was in high repute as the chief anatomist and naturalist of the time, yet in his great work of comparative anatomy and physiology not one of the young men of science imitated him-in the highest sciences he had not one true disciple". With Laennec it was different : unlike Hunter, he was "apt to teach", and had the opportunity afforded by his connection with the Hospital Necker of training numerous disciples from this and other countries, one of the most distinguished of whom (Dr. Williams) still survives. Others who, like our own Stokes and Corrigan, had not the advantage of his personal teaching, drank the knowledge from his pub- lished writings, and drew therefrom an inspiration and an impulse which carried them far into the field of discovery.

It only remains to remark that from Laennec's first observation till his death only ten years elapsed, two years of which were spent in the country, while suffering from disease which afterwards proved fatal. Few men have contributed an equal amount of such valuable work within the same space of time. Of its appreciation by men of kindred genius and pursuits, I have already given one example in the eloquent words of Dr. Stokes; let me add another in those of Dr. Addison. "Were", says Dr. Addison, "I to affirm that Laennec contributed more towards the advancement of the medical art than any other single individual, either of ancient or of modern times, I should probably be advancing a proposition which, in the estimation of many, is neither extravagant nor unjust. His work De l'Auscultation Médiat' will ever remain a monument of genius, industry, modesty, and truth. It is a work, in perusing which every succeeding page only tends to increase our admiration of the man, to captivate our attention, and to command our confidence. We are led insensibly to the bedside of his patients ; we are startled by the originality of his system; we can hardly persuade ourselves that any means so simple can accomplish so much, can overcome and reduce to order the chaotic confusion of thoracic pathology ; and hesitate not in the end to acknowledge our unqualified wonder at the triumphant confirmation of all he professed to accomplish." But is he still appreciated as he deserves? Is he still the living oracle, or rather is not his name now rarely mentioned-fast becoming a mere tradition among practitioners and students? His work has been long out of print in both languages, but neither the old nor the new Sydenham Societies have thought it worthy of a re-issue. For the one it may have been too new-not yet fossilised; and it may be supposed that the council of the new society have passed it by while translating and reediting works of inferior merit, because it is too old. I am glad, however, to see an announcement in a recent number of the Lancet that, "Thanks to the late Minister of Public Instruction, who granted a subsidy for this purpose, the Faculty of Medicine have been enabled to publish a new edition of Laennec's work upon auscultation, which has long been out of print. This is intended as a national monument to the illustrious pioneer in physical diagnosis; and it is to be sold at a low price, in order to bring it within the reach of all." The old saying seems still to be true: "They manage these things better in France."

Having touched on the prelude and the epoch of Laennec's discovery, it only remains to glance at the immediate sequel, or at what he did and what he failed to do, since to follow up the paths of investigation to which his method has led would indeed be a task equally illimitable and interminable.

- Time would fail me were I even to attempt an analysis of his work. I shall merely notice a few salient observations in the more important chapters, occasionally referring to the corrections and additions of succeeding writers.

Of his chapter on exploration of the chest it is impossible to speak too highly. Unlike most authors of new systems, he did not commence with destroying the work of his predecessors; while no mere improver he yet was not a revolutionist. Not only does he repeatedly urge the value and necessity of the study of rational symptoms, but he avails himself of those physical signs which had been observed from the time of Hippocrates by physicians and surgeons, and more especially of the discovery of percussion by Auenbrugger, whose method, he says, acquires a fresh degree of value when combined with auscultation. It must be confessed, however, that in some instances he undervalues the more ancient methods as in the case of measurement and of palpitation, and he evidently was unaware of the diagnostic value of vocal fremitus as perceived by the hand. His observations on percussion are minutely accurate, take for example the distinction he draws between the sound elicited, and the tactile sense of elasticity or the contrary. The same may be said of his account of the stethoscopic signs, of the felicitous comparisons by which he describes them and his explanation of the physical conditions indicated by them.

One serious oversight he made which had important results, namely, the non-recognition of the friction sound produced by the exudation of lymph on the serous membranes of the pleura and pericardium. Had he recognised this he would probably not have left the diagnosis of pericarditis unwritten; but he seems to have considered friction murmur to be caused by interlobular emphysema exclusively.

His chapters on the different forms of catarrh are excellent-that on dry catarrh especially so. His original description of dilatation of the bronchi deserves the eulogy of Trousseau, who pronounced it to be " complete, although probably thrown off at the first dash". He first gave a complete account of emphysema of the lungs, but erred in his explahation of the mode of genesis, as demonstrated by Dr. Gairdner, 
and perhaps also in regarding dry crepitous rattle as the pathognomonic sign of the interlobular form.

His chapter on pulmonary apoplexy is, as he himself states, original, and contains some valuable observations, $e . g$., the occasional occurrence of bellows-murmur in the heart and larger arteries; the rise of temperature, diagnostic of the supervention of intercurrent pneumonia, and the fact that in this, as in some other cases, the abstraction of blood by leeches seems sometimes to excite hæmorrhage. He does not notice the accentuation of the second sound of the pulmonary artery present in this disease and in phthisis, as well as in mitral stenosis. Dr. Balfour is the only writer who, so far as I am aware, assigns its due importance to this valuable sign in pulmonary as well as in cardiac cases. Of course, Laennec had no knowledge of the connection between hremoptysis and the hremorrhagic infarction caused by thrombus in the branches of the pulmonary artery, nor does he appear to have had any knowledge of the source of hæmorrhage in aneurisms of these arteries in the later stages of phthisis, so fully described by Rasmussen, and also by the late Dr. Cotton and by Peacock.

In his chapter on pneumonia, he gives what may be considered as a fairly complete anatomical description of the ordinary sthenic croupous form of the disease, apparently the form with which he was familiar. To his account of the physical signs I would take one exception, namely, the attributing to the crepitating râle the character of a pathognomonic sign of the first stage. His enumeration of symptoms needs only the addition of the altered pulse-ratio, the importance of which was, I believe, first insisted on by Dr. Walshe, and more thorough informaition regarding the temperature, the peculiar sensible character of which was first noticed by Dr. Addison, while Wunderlich and others have shown that the value of the thermometer is second only to that of the stethoscope in the study of this disease.

Regarding the treatment. I question if he overestimates the good effect of tartar emetic in the sthenic form of the disease, and I do not know a more plausible theory of its mode of action than his own, namely, by "promoting interstitial absorption". He bled freely, as was the fashion of the day, and may be, perhaps, the fashion of the futureonly that we know better why we bleed; not to cure pneumonia, but to relieve congestion and avert impending suffocation; urgent dyspnoea being, as Dr. Wilson Fox well observes, the only positive indication for this remedy, with the exception of a very high amount of pyrexia in the early stages.

Laennec recognises, though briefly, some exceptional forms which succeeding writers have described more fully, such as that prevailing during an epidemic of influenza in which hepatisation did not occur, or was long delayed-a form corresponding apparently to the blue pneumonia described by Sir D. Corrigan in the Dublin Hospital Gazette, and by Dr. Gordon in the twenty-second volume of the Dublin Quarterly Fournal of Nedical Science. He also refers to an epidemic form which corresponds to the pythogenic pneumonia described by Drs. Grimshaw and J. W. Moore ; and to an outbreak of it which occurred on board some of the ships of the Royal Navy in 1860 , due to ochlesis generated by overcrowding, and becoming communicable by contagion. His opinion that abscess is a comparatively rare termination of pneumonia is generally received, and the same remark applies to gangrene, of which he says: "It can scarcely be ranged among the terminations of the pulmonary inflammation, and still less can it be considered as the consequence of its intensity......It would, on the contrary, seem in most cases to approach the nature of the idiopathic gangrenes, etc."

His division into the two forms of uncircumscribed and circumscribed gangrene has been adopted by subsequent writers as being well founded.

I do not think he mentions that occasional result of pneumonia described by Rokitansky under the name of indurated hepatisation.

Of complications, Laennec refers especially to the cerebral and biliary. The former he ascribes to determination of blood to the head ; but, as he remarks that it occurred in old persons, and ran into the third stage in a few hours, one would be inclined to think the "coma" was probably due to uræmia, in which complication Dr. M'Dowel has shown that pneumonia possesses the tendency to run rapidly into purulent infiltration.

Of the biliary complication, I may remark that the acute yellow softening of Rokitansky is an occasional and invariably fatal complication of pneumonia.

His chapter on the different forms of pleuritis is full of valuable observations. I can notice but a few.

Dry pleurisy he regards as usually a mere complication of some more serious disease, as pneumonia or phthisis. He remarks on the mistake of supposing that pleuritis terminates by effusion, whereas it (the effusion) may occur in the course of a few hours from the attack. $\mathrm{He}$ anticipates the late Dr. Greene's observations on vicarious purulent expectoration in empyema. He notices the frequent confusion of chronic pleuritis with phthisis. He lays down judicious rules for paracentesis, and advocates an early operation, on the ground that compression of the lung against the spine renders the success of the operation at a later period doubtful. He observes on the sanguinolent nature of the effused fluid in cancerous pleuritis-a fact often noticed in Dublin, and fully confirmed by Dr. Bowditch, who states that, in his experience of eightyfive cases, "sanguinolent fluid, when following the first puncture, was almost certainly fatal, and a consequence of some malignant disease of the lung or pleura."

No chapter in Laennec's work displays more patient and original research than that on pulmonary phthisis, but none has been more severely criticised by two classes of pathologists, by eminent clinical physicians and histologists. For a statement of the views of the former, I may refer to the second chapter of Dr. Williams' work on Consumption, and to the writings of Drs. Addison, Graves, Andrew Clarke, and Niemeyer. It is in the researches of the histologists, however, that Laennec met his Nemesis for the depreciation of microscopic investigations; one of the many instances proving how unwise are those vaticinations of future failure and of finality in science, which seem to say to the ever advancing tide of discovery, "Thus far shalt thou come, and no farther; and here shall thy proud waves be stayed".

Virchow and Reinhardt in Germany, followed by many others in England, have initiated a controversy which, like its subject, might, to use the expression of Dr. Wilson Fox, be termed illimitable; which has led to much original microscopical research, and to many doubtful experiments on those quasi-scrofulous animals, guinea-pigs and rabbits; and to a most interesting and valuable discussion in the Pathological Society of London, in which Laennec's views, with slight modification, were advocated by Drs. Wilson Fox and Moxon-namely, that all phthisis is tuberculosis-W. Fox holding that caseous pneumonia is pneumonia running a particular course in the presence of tubercles, and Moxon maintaining that the "anatomical characters of phthisis, as seen by the unaided eye, are positively sufficient to separate it from all other pulmonary diseases, and to gather all phthisical cases into one natural group, practically coinciding with the tuberculous phthisis of Laennec and Louis". Dr. Bastian, on the other hand, considered those views so erroneous that he would expunge the word tubercle from the medical vocabulary; while Dr. Williams maintained the opinions published in his valuable work on consumption, namely, that in inflammation of the adenoid tissue, the general result and future history of the inflammatory product are determined by its composition and vital endowments; and that it is by a scrofulous type of inflammation of the adenoid tissue that miliary indurations are developed, tending to caseation, softening, and spreading, and the formation of cavities. To those who wish to see an able részimé of the opinions of the numerous British and foreign writers on this vexed question, I would recommend a perusal of Dr. Foote's lectures on tuberculosis, published in the Dublin Medical Fournal for May and July $1877 . *$ I would also direct attention to an argumentative essay by Dr. Finny on "Pulmonary Hæmorrhage as a cause of Consumption" in the same journal for May 1873, in which several cases are detailed in support of the doctrine of phthisis ab hæmoptoë; all, however, occurring in patients of a strumous diathesis.

A review of the controversy shows the balance of opinion in favour of Laennec's views, with little modification, and that not only the eminent pathologists to whom I have referred, but others so distinguished as MM. Charcot and Rindfleisch, maintain their substantial accuracy - the former stating that, to his mind, "Nothing is better established than the existence of infiltrated or discrete tubercle, as a fundamental element in the different forms of pulmonary phthisis; on the other hand, nothing is more doubtful than the existence of caseous pneumonia independent of tuberculosis, and constituting the prime agent in the phthisical process"; while the other, in his article on Tuberculosis, in Ziemssen's Cyclopadia, asserts the similarity and close

* I cannot help expressing my conviction that the views of those who, like Dr. Williams, believe in the inflammatory origin of phthisis, have an important bearing on its treatment, while the same remark applies to the treatment of those intercurrent attacks sometimes regarded (erroneously) as relapses, which ensue from exposure to cold or other acts of imprudence during the progress of the disease. Thave seen several cases in which the life of the patient was prolonged for years by the vigorous treatment of an attack of pneumonia or pleuritis, or bronchitis occurring in a more or less advanced stage of the disease ; while as regards the earlier stage, it has been my practice, in all cases in which the exciting cause was cold and the symptoms and
physical signs those of any form of inflammation or congestion, to commence by the physical signs those of any form of inflammation or congestion, to commence by the
employment of such measures as moderate local depletion (say by the application of employment of such measures as moderate local depletion (say by the application of from three to six leeches to the axillary region), counterirritation, and the free administration of iodide of potassium, and bicarbonate of potass, conjoined with seda.
tives. I could cite not a few cases in which this treatment has apparently averted tives. I could cite not a few cases in which this treatment has apparently averted advanced or the infective stage of the disease-namely, large doses (usually half a drachm) of dilute hydrochloric acid, with succus conii and the chlorides of barium and calcium, which latter, from experience, I regard (malgre the want of faith of Laennec, vide pp. 370 , 37I), with the iodide, as remedies of powerful efficacy in affections of the lymphatic system. 
connection of scrofulous infiltration and tubercle, and the mutual relations between scrofula, scrofulous inflammation, and tubercle, maintaining that, "like certain animals-guinea-pigs, rabbits, and monkeysscrofulous persons only need to have some local inflammation set up, in order to become tubercular. The tuberculosis depends on the resorption of the individual's own inflammatory products." Rindfleisch thus approaches to the views so strongly expressed by Graves in the second edition of his Clmical Medicine, as well as to the opinion of Laennec, namely, that tubercle and the matter of scrofulous glands are absolutely identical (Forbes's translation, p. 328).

But, after all, the wonder is not that Laennec's pathology should be questioned, but rather that he should have grasped so much of the truth-if not the whole truth-for, as Mr. Buckle rightly observes, "the philosophic pathologist is as different from a physician as a jurist from an advocate, or an agricultural chemist from a farmer. The two sets of functions may be united, and occasionally, though very rarely, they are, but there is no necessity for their being so." They were so united in Laennec, though in different degrees. He was a pathologist before his discovery; but ever after, his pathology was made subservient to the great object of his life-the improvement of clinical medicine by the application of physical diagnosis. To justly estimate his merits and the influence of his work, we should realise the truth, that "the progress of every science is affected more by the scheme according to which it is cultivated, than by the actual ability of the cultivators themselves"; and, as the writer I have quoted justly remarks, "whoever has reflected much on the different stages through which our knowledge of biology has successively passed, must be led to the conclusion that, while fully recognising the great merit of the (microscopic?) investigators of the animal frame, our highest admiration ought to be reserved not for those who make the discoveries, but rather for those who point out how the discoveries are to be made".

The second part of Laennec's work, though marked by great ability and originality, is confessedly inferior to the former, as also to the mass of the observations of subsequent writers. And first we observe that, while his explanations of the physical signs of the lungs may be said to have received few corrections, his theory of the sounds of the heart in the healthy and diseased states has been proved to be erroneous. Starting from a sound principle, that the ear judges more correctly of the intervals of sound than the eye of the intervals of motions corresponding to these, he yet vitiated his conclusions by ascribing to the contraction of the auricles the sound produced by the suoden tension of the semilunar valves. To estimate the important consequences of this error, which could scarcely have been committed had Laennec borne in mind the hydrostatic law of the equal pressure of fluids, we have but to recall to mind the phenomena of a case of aortic patency which Laennec seems not to have observed, but which, a very few years after, was so thoroughly investigated by Sir D. Corrigan, in a masterly memoir, which threw much light on the pathology and treatment, not only of this, but also of other diseases of the heart, showing more especially the true conditions indicating the use of digitalis in cardiac affections.

Other disciples of Laennec examined and corrected his theory by experiments on living animals, and by clinical observation-notably Drs. Hope and Williams, and I would add Dr. Billing and Mr. Bryan, whose researches have scarcely been appreciated as they deserve.

That the subject of the heart's motions and sounds continues to occupy the minds of eminent physiologists and pathologists in this and other countries, we have proofs in the most recent works on physiology, in the monographs of Walshe, Balfour, and Hayden, and in the contributions of clinical observers in the periodicals of the day.

Laennec's erroneous explanation of arterial murmurs has been amply corrected by the experimental researches of Williams and Corrigan, while the mistake he made of locating the continuous murmur heard in the neck in the carotid arteries was long since corrected by Dr. Ogier Ward, who conclusively proved that it is seated in the large veins. Another erroneous explanation is that of the genesis of a loud musical murmur audible at some distance from the patient, since proved by the clinical observations of Drs. Banks, Stokes, and Corrigan to be due to the presence of a vibrating tongue in the heart or aorta.

With regard to the application of physical diagnosis to the diseases of the heart, Laennec has been accused of an amount of confidence which is not justified by its results in his own hands. But such an accusation does not appear to be warranted by his language, for he not only rather over-estimates the difficulty "of the study of the heart's actions in health", but, while maintaining the insufficiency of the general symptoms-which he has sketched with great terseness and power, but without any attempt at differentiation-to characterise or indicate disease of the heart, and the consequent necessity of recourse to mediate auscultation, he adds, that "even it more frequently fails in this case than in any of the other diseases which it is calculated to discover". And again, that in these diseases "we shall be most liable to commit grievous errors in diagnosis, more especially if we restrict our exploration to a few minutes, and fail to take into account the general symptoms and the diseases which may complicate those of the heart".

Of the additions made to Laennec's description of diseases of the heart, the most remarkable is the case of pericarditis. We cannot realise his admission that the stethoscope scarcely furnishes us with any certain signs of this disease, now, when the contrary is so generally acknowledged. But for many years after Laennec, the general belief, as enunciated by Andral and others, was that the diagnosis of pericarditis could only be arrived at indirectly and by a process of exclusion. It was reserved for Dr. Stokes to expound so fully the physical diagnosis of this disease, as to leave " what had been the most difficult the most easy of detection in medicine" (Sibson). True, the friction murmur had been noticed by Collin, and Watson, but these were scattered rays converging to and concentrated in a burning focus in the exhaustive memoir of Stokes.

Perhaps no chapter in Laennec's work is more worthy of admiration than that on softening of the heart in fever. His description of the colour and consistence of the organ; of the analogous condition of other muscles; of the diminution of the heart's impulse and occasional loss of its sounds; of the slowness of its action and occasional fits of excitement; of its non-inflammatory nature, and of the indications for wine, which, he says, "is indicated in case the affection supervenes to a severe fever, and if the paticnt bears it well"; and of its curability in convalescence under tonic treatment, are excellent; and I may add that he evidently recognised the coexistence of softening and hypertrophy (the failing hypertrophy of Fothergill), although ignorant of the fact, since demonstrated by Rindfleisch, that this febrile softening is a true fatty degeneration. I need not remind my hearers how these observations, with those of Louis, suggested the admirable researches of Dr. Stokes, and led to the placing of the indications for the exhibition of wine in typhus upon a sound and certain foundation.

On the great subject of fatty degeneration of the heart, Laennec's claims to originality have been ignored by some writers, while others, as the author of the article in Ziemssen's Cyclopadia, have fully recognised them. He was, in fact, familiar with both forms, - fatty infiltration and fatty degeneration,- the latter of which he defines to be an actual transformation of the muscular substance into a substance possessing all the chemical and physical properties of fat, thus anticipating the idea which Dr. Quain afterwards developed and proved to be a fact by the original and elaborate experiments detailed in his memorable essay in the Medico-Chirurgical Transactions, researches of which Sir James Paget says: "Dr. Quain has candidly referred to many previous observers by whom similar changes were recognised, but the honour of the full proof and of the right use of it belongs to himself alone."

Perhaps no subject in medicine has since occupied a larger share of the attention of the profession than this, as is proved by the contributions of numerous English and continental writers; the recorded cases in the Transactions of the Pathological Societies of London and Dublin; the monographs of Walshe, Balfour, Fothergill (who gives a masterly description of the general symptoms); of Hayden, who has carefully collected and tabulated the cases reported since Dr. Quain's memoir with many of his own; and of Stokes, who first, I believe, expounded the differential diagnosis of degeneration of the right and left cavities, based upon the preponderance of respiratory or cerebral secondary affections.

Not to follow this review further, I may remark that a careful perusal of these chapters will disclose some observations and suggestions worthy of notice; such, for example, as his account of the signs of contraction of the mitral orifice (pp. 647-8), as his observation that "the severest diseases of the heart consist in defects of proportion, and yet a slight disproportion between it and other organs, or between some of its own constituent parts, is compatible with a state of health"; that dilatation of the right ventricle without hypertrophy is of rare occurrence ; that digitalis is of no benefit in hypertrophy; that simple hypertrophy without dilatation is much more rare in the right than in the left ventricle that intermission of the pulse is often due to the alternate feeble contraction of the ventricle; that the capillary circulation is in some sort independent of the general, a fact now recognised by pathologists ; and, not to multiply instances, his theory of angina pectoris, of which Dr. L. Clarke says, "Laennec's view of the proximate cause has been materially supported by recent inquiries" (Pathological Transactions, vi).

What has been Laennec's influence on practice, on clinical teaching, and on the public estimate of medicine? By his introduction of differential diagnosis-the essential prerequisite of scientific therapeutics-the treatment of diseases of the chest, previously directed to a name, a 
group of symptoms, or often to a single symptom supposed to be pathognomonic of a certain affection, has become differentiated; and a case of pneumonia is no longer treated as one of pleuritis, nor one of diseased heart ; or of emphysema as one of hydrothorax - the universal practice during the preceding era. Auscultation, also, by enabling us to recognise the tendency of diseases to recovery, or the contrary, becomes a powerful adjuvant in their treatment. Moreover, we have, in the recognition of the vital condition and innervation of the heart, a most valuable guide to the treatment of various diseases, notably with regard to the exhibition of wine in fever, and the treatment of the cerebral anzemia of fatty heart and of other cerebral affections; and, in the field of preventive medicine, auscultation co-operates by detecting the germs and vestiges of disease, as the early signs of phthisis or the organic sequelæ of acute disease.

With regard to Laennec's influence on clinical instruction, we might well ask what would such instruction be, if physical diagnosis were omitted? Without it, the knowledge gained at the bedside would be mere cramming. "Teaching", says Dr. Moxon, "is the storing of knowledge-it may be done quickly. Training is the creation of an organ for use of knowledge-it needs much time, it is a slow process. The trainer has to convert the pupil's knowledge into motive, his desire into patience, his will into skill. Every good trainer aims to raise up in his pupil's mind a self-training faculty, which shall itself continue to train, more and more, knowledge into motive. By such training, knowledge becomes power." This is exactly what physical diagnosis does. Following the method of Laennec, the clinical teacher trains the pupil to the use of his senses in the observation of sensible phenomena, then to the associating these with the physical conditions from which they arise, and finally to their relations with principles of pathology and of treatment. No greater improvement has ever been effected in medical education than by the introduction of this method into hospital teaching by the late Dr. Graves, as described in his work on clinical medicine.

It were more easy to say what should be than what is the influenceindirect, of course- of Laennec on the public estimate of medicine. This, we know, has never been high ; and physicians have been the objects of satire for centuries. A hundred years ago, Zimmerman wrote : "I sometimes hear pretended wits affecting, with a tone of raillery, that physic is still such as it was in the time of Hippocrates, and that the best informed physicians know only that which he knew." Later, we have the question gravely propounded by Sir William Hamilton : "Has the practice of medicine made a single step since Hippocrates ?" and the late Dr. Symonds, in a Presidential Address on this subject-since published in his Miscellanies-referred to passages in two leading reviews of the day, too long for quotation, both representing medicine as uncertain, always changing, resting on arbitrary assumption, etc. One oracle asks : "But can any one at this moment seriously declare that there is such a thing as a science of medicine?" "What there is is this : there are a few facts-a very few-distinctly known and beyond the reach of controversy, and the number of these increases but slowly, if it sensibly increases at all."

Our answer to such nonsense is to point to what Laennec has done. Is the influence of medicine in directly saving life called in question, we may refer to the physical diagnosis of cases which, without medical or surgical interference, run on inevitably to a fatal termination: e.g., of empyema, or of a foreign body in the bronchus; to the advantage of the early detection and treatment of phthisis, or certain diseases of the heart, or aneurism of the aorta.

In regard of that power of prognosis which Hippocrates recommended physicians to cultivate, with a view to securing the confidence of those who consulted them, I need not remind you of what we owe to Laennec; and in the detection of latent disease, in the numerous cases in which the aid of the physician is sought by insurance companies or Governmental departments, from whom do we obtain help so largely as from Laennec, either alone or in conjunction with Bright? If, then, we challenge the public estimate for our profession as a science, it is to Laennec we owe much of the grounds of our claim; and if it be said that the art is conjectural, to a portion, at least, we say he has contributed a degree of certainty almost amounting to law.

"As soon as any department of knowledge", says Mr. Buckle, "has been generalised into laws, it contains, either in itself or its applications, three distinct branches : namely, inventions, discoveries, and method."

Laennec combined all these. His invention was as perfect as simple, tried by the test for such-" will it work ?" His discoveries have led to others, only second in importance to his own, by those who have adopted his method. He was not a generaliser like Cullen, and perhaps scarcely deserves the eulogy of Sir William Hamilton on that great man, whom he seems to praise for that " he had not made the discovery of a single phenomenon". He did not undervalue theory, which he calls the "scaffolding of science"; he reasoned-not downwards from general principles to facts, but in the contrary direction; and having seen and seized on the "enlightening fact", and pursued what Bacon calls the "experimenta lucifira" through a lengthened series of observations on the living and on the dead, he developed and has bequeathed to us a method "comprehensive and exact" in its induction, which, however it may hereafter "be further polished and illustrated, and accommodated for use and practice", can never be dispensed with in the present, or superseded in a future age of medicine. To him we may fitly apply Cowley's well-known lines on Bacon :

"From these and all long errors of the way

In which our wandering predecessors went,

And, like the old Hebrews, many years did stray

In deserts but of small extent ;

Bacon, like Moses, led us forth at last ;

The barren wilderness he past,

Did on the very border stand

Of the blest promised land,

And from the mountain top of his exalted wit

Saw it himself, and showed us it."

Allow me to trespass on your patience for a moment longer, while I express my personal regret for one whose recent death, I may truly say, is deplored by the entire profession ; and whose loss to this Association may be judged of by this, that his last public act, so far as I am aware, was in reference to the arrangements for the present meeting.

On reading the short biography, accompanying the announcement of his death, in the BRITISH MEDICAL JOURNAL, I was struck by the resemblance of his career to that which I have feebly attempted to sketch.

Like Laennec, Dr. Murchison was a diligent and highly distinguished student ; he, also, early devoted himself to the cultivation of pathology and clinical medicine, and became a great clinical teacher; like Laennec, he compressed the labours of a long life into a comparatively short period; and like him, his name will ever be associated with a great work-a work which must live, inasmuch as it is not only the most comprehensive and exhaustive which has ever appeared on the subject, but also marks the epoch of that sound and scientific classification of fevers which the late Dr. Parkes, in his admirable address in 1873 , pronounced to be probably "our greatest advance in practical medicine". That advance, mainly due to the researches of Stewart and Jenner, has been secured, and rendered permanent, and illustrated by the great work of Charles Murchison.

West KENT. - This is an extremely interesting report, and, what is unfortunately too rare amongst reports of this character, is perfectly comprehensible to the outside reader. It commences with a brief description of the extent and character of the district, and then proceeds to compare, in a variety of valuable tables, the mortality for 1878 with that for preceding years. There is evidence throughout of the zeal and promptitude of Dr. Baylis, who seems to be especially successful in stamping out threatened epidemics of disease. For instance, small-pox, which broke out in the district 27 times during the year, was only able to make headway in one instance, where the disease was unrecognised and unreported. The effect of this was that the seeds of infection were sown broadcast ; and, before the disease could be quelled, 69 cases, and 13 deaths had occurred. Nearly all these 27 outbreaks were caused by importations from London; and it is a matter for regret, therefore, that only one of the twelve authorities in the combination has provided a hospital for infectious diseases. The West Kent district stands alone in having taken seriously in hand what may well be called county drain. age. One large scheme for draining a considerable part of the district has been nearly perfected; and the works for another to drain the Darenth Valley, are about to be commenced. Considering the difficulties which small districts have to encounter in planning drainage works for themselves, we could wish that the system which has been adopted in West Kent should be largely extended. During last year, 2,559 deaths occurred in the whole district, a number equal to a rate of 16.8 per 1,000 , as against 16.2 in $1877,16.6$ in 1876 , and 18.5 in 1875 . Of these 2,599 deaths, 608 were children under one year, 282 in children between $I$ and 5 , and 816 in persons above 60 years of age. Zymotic diseases caused 376 deaths, 23 of these being from small-pox, 83 from whooping-cough, 44 from fevers, and 94 from diarrhoea. The diarrhœa deaths were not only the most numerous, but showed the largest increase upon the average. Whooping-cough was fatally prevalent, being five per cent. above the local average. The fever deaths were equal to the average ; but measles, scarlatina, and diphtheria taken together show a decrease of no less than one half. The general impression left upon the mind after reading Dr. Baylis's account of the sanitary action in the several districts is that, at least in this combination, the Public Health Act is working well, and that to Dr. Baylis the largest share of this gratifying result is due. 